\title{
Form of calf diet and the rumen. II: Impact on volatile fatty acid absorption
}

\author{
T. T. Yohe, ${ }^{1}$ H. Schramm, ${ }^{2}$ R. R. White, ${ }^{3}$ M. D. Hanigan, ${ }^{1}$ C. L. M. Parsons, ${ }^{1}$ H. L. M. Tucker, ${ }^{1}$ B. D. Enger, ${ }^{1}$ \\ N. R. Hardy, ${ }^{1}$ and K. M. Daniels ${ }^{1 *}$ \\ ${ }^{1}$ Dairy Science Department, Virginia Polytechnic Institute and State University, Blacksburg 24061 \\ ${ }^{2}$ Virginia Maryland Regional College of Veterinary Medicine, Virginia Polytechnic Institute and State University, Blacksburg 24061 \\ ${ }^{3}$ Animal and Poultry Sciences Department, Virginia Polytechnic Institute and State University, Blacksburg 24061
}

\section{ABSTRACT}

Diet is known to affect rumen growth and development. Calves fed an all-liquid diet have smaller and less developed rumens and a decreased ability to absorb volatile fatty acids (VFA) compared to calves fed both liquid and dry feed. However, it is unknown how rumens respond when challenged with a defined concentration of VFA. The objective of this study was to assess the effects of 2 different feeding programs on VFA absorption in preweaned calves. Neonatal Holstein bull calves were individually housed and randomly assigned to 1 of 2 diets. The diets were milk replacer only (MRO; $\mathrm{n}$ $=5$ ) or milk replacer with starter (MRS; $\mathrm{n}=6)$. Diets were isoenergetic $(3.87 \pm 0.06 \mathrm{Mcal}$ of metabolizable energy per day) and isonitrogenous $(0.17 \pm 0.003 \mathrm{~kg} / \mathrm{d}$ of apparent digestible protein). Milk replacer was $22 \%$ crude protein, $21.5 \%$ fat (dry matter basis). The textured calf starter was $21.5 \%$ crude protein (dry matter basis). Feed and ad libitum water intakes were recorded daily. Calves were exposed to a defined concentration of VFA buffer (acetate $143 \mathrm{~m} M$, propionate $100 \mathrm{~m} M$, butyrate $40.5 \mathrm{mM}) 6 \mathrm{~h}$ before euthanasia on d $43 \pm 1$. Rumen fluid samples were obtained every 15 to $30 \mathrm{~min}$ for $6 \mathrm{~h}$ to measure the rate of VFA absorption. Rumen tissues were obtained from the ventral sac region and processed for morphological and immunohistochemical analyses of the VFA transporters monocarboxylate transporter 1 (MCT1) and 4 (MCT4). Body growth did not differ between diets, but empty reticulorumens were heavier in MRS than MRO calves (0.67 vs. $0.39 \pm$ $0.04 \mathrm{~kg})$ and MRS calves had larger papillae areas $(0.76$ vs. $15 \pm 0.08 \mathrm{~mm}^{2}$ ). We observed no differences between diets in terms of the abundance of MCT1 and MCT4 per unit area. These results indicate that the extrapolated increase in total abundance of MCT1 or MCT4 in MRS calves was not due to increased transporter

Received February 7, 2019.

Accepted May 1, 2019.

*Corresponding author: danielsk@vt.edu density per unit area. Modeled VFA absorption metrics (flux, $\mathrm{mmol} / \mathrm{h}$, or $6 \mathrm{~h}$ absorbed VFA in $\mathrm{mmol}$ ) were not different across diets. These results demonstrate that the form of calfhood diet, whether solely MR or MR and starter, does not alter VFA absorption capacity when the rumen is exposed to a defined concentration of VFA at 6 wk of age.

Key words: dairy, calf nutrition, ruminant physiology, short-chain fatty acids, transporter

\section{INTRODUCTION}

At birth, the dairy calf has an undeveloped rumen (Tamate et al., 1962; Warner and Flatt, 1965) that must grow and develop to support ruminant metabolism. Both rumen growth (an increase in organ size) and rumen development (a change in function) are stimulated when the calf starts consuming dry feed (i.e., calf starter; Warner et al., 1956; Flatt et al., 1958; Connor et al., 2013). Calves that remain on a liquid-only or primarily liquid diet have underdeveloped rumens. The physical characteristics of underdeveloped rumens include small overall rumen size and low papillae dimensions and mass (Lengemann and Allen, 1959; Harrison et al., 1960; Tamate et al., 1962). Feeding a liquid-only diet limits the growth of the rumen, but it promotes ADG during the preweaning period when calves can consume large amounts of milk replacer (MR) or milk (Jasper and Weary, 2002; Schäff et al., 2016; Frieten et al., 2017). Encouraging ADG during the preweaning period is a common goal among producers and has been shown to increase first lactation milk yield (Soberon et al., 2012; Soberon and Van Amburgh, 2013; Gelsinger et al., 2016), so producers have an incentive to promote ADG by feeding a diet heavy in MR or milk preweaning. Despite limiting dry feed intake and thus limiting rumen growth and development (Warner et al., 1956; Flatt et al., 1958; Connor et al., 2013), we do not know the consequences of these 2 feeding strategies (i.e., promoting liquid or promoting dry feed intake) for the ability of the rumen to absorb VFA in the preweaning calf. 
Most of the existing data on rumen VFA absorption in calves was generated in the 1960s. Although this information is useful, given the advances in calf nutrition and the genetic progress made via selection for high-yielding dairy cows since then, the topic is worthy of reinvestigation because of improvements in the methodologies currently used to measure VFA absorption. Considering the limited volume capacity of the preweaned calf rumen (Tamate et al., 1962; Warner and Flatt, 1965) one might assume that the ability of the rumen to absorb VFA is decreased when compared with a developed calf rumen. However, this assumption has not been empirically tested. This study assessed the "maximal" VFA absorptive ability of the rumen tissue of 6 -wk-old calves fed diets designed to generate undeveloped and developed rumens. Our hypothesis was that when exposed to defined concentrations of VFA, calves fed a diet of liquid and solid feed meant to stimulate rumen development would have an enhanced ability to absorb VFA compared to calves fed a liquidonly diet. The findings had the potential to influence the way calves are fed if either of the feeding strategies resulted in more efficient VFA absorption.

\section{MATERIALS AND METHODS}

\section{Animals, Treatments, and Experiment}

This experiment was approved by the Virginia Tech Institutional Animal Care and Use Committee (protocol \#16-165) and conducted from February 2017 to May 2017. Full experimental details are described in a companion paper (Yohe et al., 2019). Briefly, 12 neonatal Holstein bull calves were purchased from a single farm and transported approximately $240 \mathrm{~km}$ to Virginia Tech. Calves arrived at Virginia Tech in 1 of 2 arrival periods ( $\mathrm{n}=6$ per period): period 1 calves were on site from February 17, 2017, to April 2, 2017, and period 2 calves were on site from April 11, 2017, to May 25, 2017. Initial calf BW averaged $43.67 \pm 0.55 \mathrm{~kg}$ (mean $\pm \mathrm{SEM}$ ), and initial calf age averaged $2.5 \pm 0.14$ $\mathrm{d}$ (mean \pm SEM).

As calves arrived at Virginia Tech, a single jugular blood sample was collected for serum IgG determination (to assess passive transfer of immunity), and calf BW, hip height, and withers height were measured. After initial measurements had been obtained, each calf was moved into an individual pen that contained a rubber mat and frequently laundered cotton towels for bedding. Pens were located in a temperature-controlled room at Virginia Tech, where the calves remained for the duration of the experiment. Calves had visual and auditory contact with the other calves, but no physical contact.
Within $24 \mathrm{~h}$ of their arrival at Virginia Tech, calves were balanced by age, BW, serum IgG, and dam lactation number and split into 2 dietary treatment groups: milk replacer only (MRO; $\mathrm{n}=5$ ) or milk replacer and calf starter (MRS; $\mathrm{n}=6$ ). A period $2 \mathrm{MRO}$ calf died at 2 wk of age from septicemia and was not replaced; its death was not treatment-related. Both dietary treatment groups were fed MR (22\% CP as-fed, $20 \%$ fat as-fed; Ledger, Southern States Cooperative Inc., Richmond, VA) twice daily at 0700 and $1900 \mathrm{~h}$; water was available ad libitum. The calf starter offered to MRS calves was a textured feed (18\% CP as-fed; Grower, Southern States Cooperative Inc.). The MRO and MRS treatment diets were formulated to be isocaloric (based on $\mathrm{ME}$ ) and isonitrogenous (based on apparent digestible protein; ADP; NRC, 2001) to negate ME or N supply as confounding factors. A detailed description of the diets is presented in a companion paper (Yohe et al., 2019), but a brief description of the diets follows. The MRO calves were offered a static amount of MR for the duration of the trial. In contrast, the MRS calves were fed decreasing amounts of MR throughout the trial to accommodate the planned increase in calf starter intake (Yohe et al., 2019); this design maintained the necessary energy (formulated to be $4.0 \mathrm{Mcal} / \mathrm{d}$ of ME throughout the 6 wk trial) and protein (formulated to be 0.198 $\mathrm{kg} / \mathrm{d}$ of ADP on average throughout the 6 -wk trial) to meet isocaloric and isonitrogenous constraints. The nutrient composition of the diets is listed in Table 1.

At $10 \mathrm{~d}$ of age, the calves underwent rumen cannulation surgery, performed similarly to that described by Kristensen et al. (2010). The surgically placed rumen cannula (2.75 i.d.) was the same design used in Lesmeister and Heinrichs (2004), Suarez-Mena et al. (2015), and Suarez-Mena et al. (2016). The cannula opening was plugged with a \#6 rubber laboratory stopper.

Termination of the trial was completed over 3 consecutive days ( $\mathrm{d} 42$ to 44 ) with 2 calves killed each day (1 per treatment). On the final day of the trial, each calf underwent a washed rumen procedure adapted from Storm et al. (2011). The procedure involved evacuating the rumen using a vacuum-assisted collection device, washing the rumen with warm tap water and warm wash buffer (Table 2), and then filling the rumen with an experimental VFA buffer (Table 2) as described in Yohe et al. (2018). For this, starting at $0 \mathrm{~h}$ the experimental VFA buffer was introduced (Table 2), the primer dose of LiCoEDTA (40 mL at $15 \mathrm{mg} / \mathrm{mL}$ ) was given, an initial baseline sample of rumen fluid was collected, and then continuous LiCoEDTA infusion (0.158 $\mathrm{mg} / \mathrm{mL}$ ) was administered through the rumen cannula. We then collected rumen fluid samples over the next 6 $\mathrm{h}$ to assess liquid passage rate (LiCoEDTA) and VFA absorption. The sampling procedure is described in 
Table 1. Chemical composition (\% of DM unless otherwise noted) of milk replacer and textured calf starter fed to calves throughout the 6 wk trial

\begin{tabular}{lcc}
\hline Chemical composition & $\begin{array}{c}\text { Milk } \\
\text { replacer }\end{array}$ & $\begin{array}{c}\text { Textured } \\
\text { calf starter }^{2}\end{array}$ \\
\hline DM & 96.2 & 85.8 \\
CP & 22.4 & 21.5 \\
Fat (ether extract for starter) & 21.5 & 3.95 \\
NDF & - & 19.0 \\
ADF & - & 9.3 \\
Starch & - & 27.7 \\
Ash & 9.49 & 9.36 \\
ME $^{3}(\mathrm{Mcal} / \mathrm{kg})$ & 4.74 & 3.09 \\
\hline
\end{tabular}

${ }^{1}$ Milk replacer was fed to both treatments $(22 \% \mathrm{CP}$ and $20 \%$ fat, as fed; Ledger, Southern States Cooperative Inc., Richmond, VA) and included milk protein and animal fat sources.

${ }^{2}$ Textured calf starter was fed to milk replacer and starter (MRS) calves (18\% CP, as fed; Grower, Southern States Cooperative Inc.) and contained processed grains from plant protein sources, including cracked corn and oats.

${ }^{3}$ Both milk replacer and starter ME were calculated using equations from NRC (2001). Milk replacer ME $=(0.057 \times \mathrm{CP} \mathrm{DM} \%+0.092 \times$ fat $\mathrm{DM} \%+0.0395 \times$ lactose $\mathrm{DM} \%) \times 0.93 ;$ starter $\mathrm{ME}=(1.01 \times$ digestible energy -0.45$)+0.0046 \times($ ether extract -3$)$.

detail by Yohe et al. (2018), but briefly, in this study we obtained a total of 19 samples of rumen fluid $(\sim 5$ to $10 \mathrm{~mL}$ per sample) using a $60 \mathrm{~mL}$ syringe, drawing fluid from the custom-made sampling device over the $6 \mathrm{~h}$ infusion/sampling period (starting with time 0) for VFA analysis and cobalt determination. The initial 5 to $10 \mathrm{~mL}$ drawn up by syringe were discarded (sample line dead volume). After the final sample was collected, calves were killed and tissue samples collected for further analyses.

\section{Analytical Procedures}

Tissue Collection and Gross Rumen Measurements. Calves were killed on d $43 \pm 1$, approximately 7 to $9 \mathrm{~h}$ after their last feeding. Although feed had been withheld, calves were undergoing the VFA absorption experiment, in which their rumen was exposed to a buffer containing higher concentrations of VFA than typically found in calves at 6 wk of age. At slaughter, samples were taken for rumen morphometric analyses according to our previously described methods (Yohe et al., 2015). Briefly, the full stomach and reticulorumen were weighed and then evacuated for empty reticulorumen weight determination. Rumen samples intended for gene expression and histological analyses were obtained from the cranial ventral sac region of the rumen using a punch biopsy tool with an internal diameter of $2.54 \mathrm{~cm}$ or securing an approximately $2.54 \times 7.62 \mathrm{~cm}$ section of tissue to a tongue depressor, respectively. Representative full-thickness rumen biopsy samples were fixed
Table 2. Wash and experimental VFA buffers used throughout the rumen wash, evacuation, and sampling protocol

\begin{tabular}{lcc}
\hline $\begin{array}{l}\text { Chemical composition } \\
(\mathrm{mmol} / \mathrm{L})\end{array}$ & $\begin{array}{c}\text { Wash } \\
\text { buffer }\end{array}$ & $\begin{array}{c}\text { Experimental } \\
\text { VFA buffer }\end{array}$ \\
\hline $\mathrm{NaCl}$ & 106.01 & 20.01 \\
$\mathrm{NaHCO}$ & 24.00 & 24.00 \\
$\mathrm{NH}_{4} \mathrm{Cl}$ & - & 2.50 \\
$\mathrm{NaOH}$ & 6.50 & 212.03 \\
$\mathrm{KOH}$ & 19.99 & 19.99 \\
$\mathrm{~K}_{2} \mathrm{HPO}_{4}$ & 2.00 & 2.00 \\
$\mathrm{CaCl}_{2}$ & 1.51 & 1.50 \\
$\mathrm{MgCl}_{2}$ & 1.50 & 1.50 \\
$\mathrm{Acetic}$ acid & - & 143.02 \\
Propionic acid $_{\text {Butyric acid }}$ & - & 100.01 \\
$\mathrm{HCl}^{1}$ & - & 40.58 \\
$\mathrm{pH}^{1}$ & 49.72 & - \\
\hline
\end{tabular}

${ }^{1} \mathrm{pH}$ was adjusted to a target of 5.8 .

in $10 \%$ neutral buffered formalin for $24 \mathrm{~h}$ and then switched to $70 \%$ ethanol before being processed and readied for immunohistochemical staining.

Real-Time Quantitative PCR. A more detailed description of the real-time quantitative PCR (qPCR) procedure is provided in the companion paper (Yohe et al., 2019). Briefly, samples from the ventral sac region sample of the rumen were used to assess the relative gene abundance of the rumen epithelial transporters of interest. The list of rumen epithelial transporters and reference genes used during qPCR analysis is shown in Table 3.

Immunohistochemistry. Fixed rumen samples stored in $70 \%$ ethanol routinely processed (Leica TP 1020; Leica Microsystems Inc., Buffalo Grove, IL), embedded in paraffin, cut to 5 - $\mu \mathrm{m}$ thickness on a microtome (model HM 340 E; Micron International GmbH, Munich, Germany), and mounted onto positively charged glass microscope slides (Yohe et al., 2015). A more detailed description of the immunohistochemistry procedures is provided in the companion paper (Yohe et al., 2019); the procedures were based on previously described methods (Daniels et al., 2009; Tucker et al., 2016). A brief description is provided here. The VFA transporter proteins identified through immunohistochemistry were monocarboxylate transporter 1 and monocarboxylate transporter 4 (MCT1 and MCT4, respectively). Primary antibodies used included antiMCT1 at 1:3,000 dilution (chicken polyclonal; catalog no. AB1286I; EMD Millipore, Burlington, MA) and anti-MCT4 at 1:250 (rabbit polyclonal; catalog no. AB3314P; EMD Millipore). Tissue sections received $100 \mu \mathrm{L}$ of the primary antibody or diluent as a negative control and were incubated at $4^{\circ} \mathrm{C}$ overnight. Primary antibody solutions were removed, sections were washed, and all tissue sections received $100 \mu \mathrm{L}$ of the fluorescent 
secondary antibody solution, which were either goat anti-chicken IgG at 1:200 (catalog no. A11042; Thermo Fisher Scientific, Waltham, MA) for MCT1 or goat anti-rabbit IgG at 1:200 (catalog no. A11037; Thermo Fisher Scientific) for MCT4. Protein abundance and localization of both MCT1 and MCT4 were quantified in the following manner. Fourteen digital images per calf were acquired at $40 \times$ magnification using a Nikon Eclipse E600 epi-fluorescence microscope fitted with a Texas Red filter cube and a Nuance FX Multispectral Imaging System (Perkin-Elmer, Waltham, MA). To assess the intensity of the signal without confounding the data within the tissue antigen of interest, each picture was taken at the same wavelength and exposure time (MCT1: $625 \mathrm{~nm}$ wavelength, $275 \mathrm{~ms}$ exposure time; MCT4: $625 \mathrm{~nm}$ wavelength, $375 \mathrm{~ms}$ exposure time). Monochrome images were opened with and analyzed in Image-Pro Plus version 7.0 (Media Cybernetics. Rockville, MD). The rumen epithelium was outlined using a freehand drawing tool, designating areas of interest. The sum of the intensity in areas of interest was calculated by an algorithm in Image-Pro Plus (Media Cybernetics). The staining intensity sum was then divided by the measured area of the area of interest for each image to yield measurements expressed as sum of intensity $/ \mu^{2}$. This approach was selected because of the non-nuclear and diffuse staining patterns of both MCT1 and MCT4 (Figures 1 and 2).

VFA Absorption and Codetermination. At designated sampling times, approximately 5 to $15 \mathrm{~mL}$ of strained rumen fluid were collected and stored at $-20^{\circ} \mathrm{C}$ in pyrolized glass screwtop tubes for later VFA analysis. Volatile fatty acids underwent derivatization and were then analyzed by gas chromatography using a method adapted from Kristensen (2000). Samples were run on a Thermo Electron Polaris Q mass spectrometer (Thermo Fisher Scientific Inc.) in tandem with a Thermo Electron Focus gas chromatograph (Thermo Fisher Scientific, Inc.) using XCalibur software version 1.4 (Thermo Fisher Scientific Inc.). We used a Varian FactorFour capillary column VF-170ms $(30 \mathrm{~m}, 0.25$ $\mathrm{mm}, 0.25 \mu \mathrm{m})$. We loaded $1 \mu \mathrm{L}$ of derivatized sample, with the inlet temperature set to $225^{\circ} \mathrm{C}$ on a split ratio of 80 running a constant flow of helium carrier gas set to $1.2 \mathrm{~mL} / \mathrm{min}$. The gas chromatograph was initiated at $75^{\circ} \mathrm{C}$, ramped at $5^{\circ} \mathrm{C} / \mathrm{min}$ to $135^{\circ} \mathrm{C}$, then at $40^{\circ} \mathrm{C} /$ min to $225^{\circ} \mathrm{C}$. The mass spectrometer was programmed to run in positive selected ion monitoring mode, collecting 3 consecutive segment $m / z$ pairs for acetate (43, $47)$, propionate $(57,59)$, and butyrate $(71,73)$ in that elution order. The processing method used to integrate the area under the curves for each $m / z$ used the International Conference on Computer and Information Science (ICIS) algorithm.

At designated sampling times, approximately 5 to 15 $\mathrm{mL}$ of strained rumen fluid were collected and stored at $-20^{\circ} \mathrm{C}$ in plastic tubes for later Co analysis. Initially, samples underwent nitric acid digestion using method 3030H (EPA, 1998) to remove organic matter. After removal of all organic material, samples were resuspended in $50 \mathrm{~mL}$ mineral-free water and sent to the Virginia Tech Soil Testing Laboratory (Blacksburg, VA) for Co determination via inductively coupled plasma atomic emission spectroscopy.

Table 3. Real-time quantitative PCR information for select genes

\begin{tabular}{|c|c|c|c|c|c|}
\hline Gene symbol $^{1}$ & Primer $^{2}$ & Primer $\left(5^{\prime}-3^{\prime}\right)$ & $\begin{array}{c}\text { Annealing } \\
\text { temperature }\left({ }^{\circ} \mathrm{C}\right)\end{array}$ & $\begin{array}{l}\text { Amplicon } \\
\text { size (bp) }\end{array}$ & $\begin{array}{l}\text { GenBank } \\
\text { accession no. }\end{array}$ \\
\hline$M C T 1$ & F: 352 & GTCATTGGAGGTCTTGGGCT & 62.6 & 129 & NM_001037319.1 \\
\hline MCT2 & R: 445 & GCCATTCGCTACAGGTCGTT & & & \\
\hline \multirow[t]{2}{*}{$\mathrm{MCT}_{4}$} & F: 173 & GTGACACAGCCTGGATCTCC & 64.5 & 150 & NM_001109980.1 \\
\hline & R: 322 & AGAAGGACGCAGACACCATG & & & \\
\hline \multirow[t]{2}{*}{ NHE2 } & F: 1602 & CGAGCAGCTCTACATCCTGG & 63.0 & 129 & XM_604493.6 \\
\hline & R: 1730 & ATGCCAGCAAACACGTCAAC & & & \\
\hline \multirow[t]{2}{*}{ NHE3 } & F: 1560 & CCTCATGAGAAGGTCGGCTC & 63.0 & 129 & NM_001192154.1 \\
\hline & $\mathrm{R}: 1688$ & GAACGGATGAAAGCCAGGGA & & & \\
\hline \multirow[t]{2}{*}{ RPS9 (reference) } & F: 122 & GTGAGGTCTGGAGGGTCAAA & 62.4 & 108 & BC148016.1 \\
\hline & R: 229 & GGGCATTACCTTCGAACAGA & & & \\
\hline RPS15 (reference) & F: 183 & CAAGGCCAAGAAAGATGCGC & 62.4 & 147 & NM_001024541.2 \\
\hline
\end{tabular}

${ }^{1} \mathrm{MCT}=$ monocarboxylate transporter; NHE $=$ sodium-hydrogen exchanger; RPS $=$ ribosomal protein.

${ }^{2} \mathrm{~F}=$ forward; $\mathrm{R}=$ reverse. 

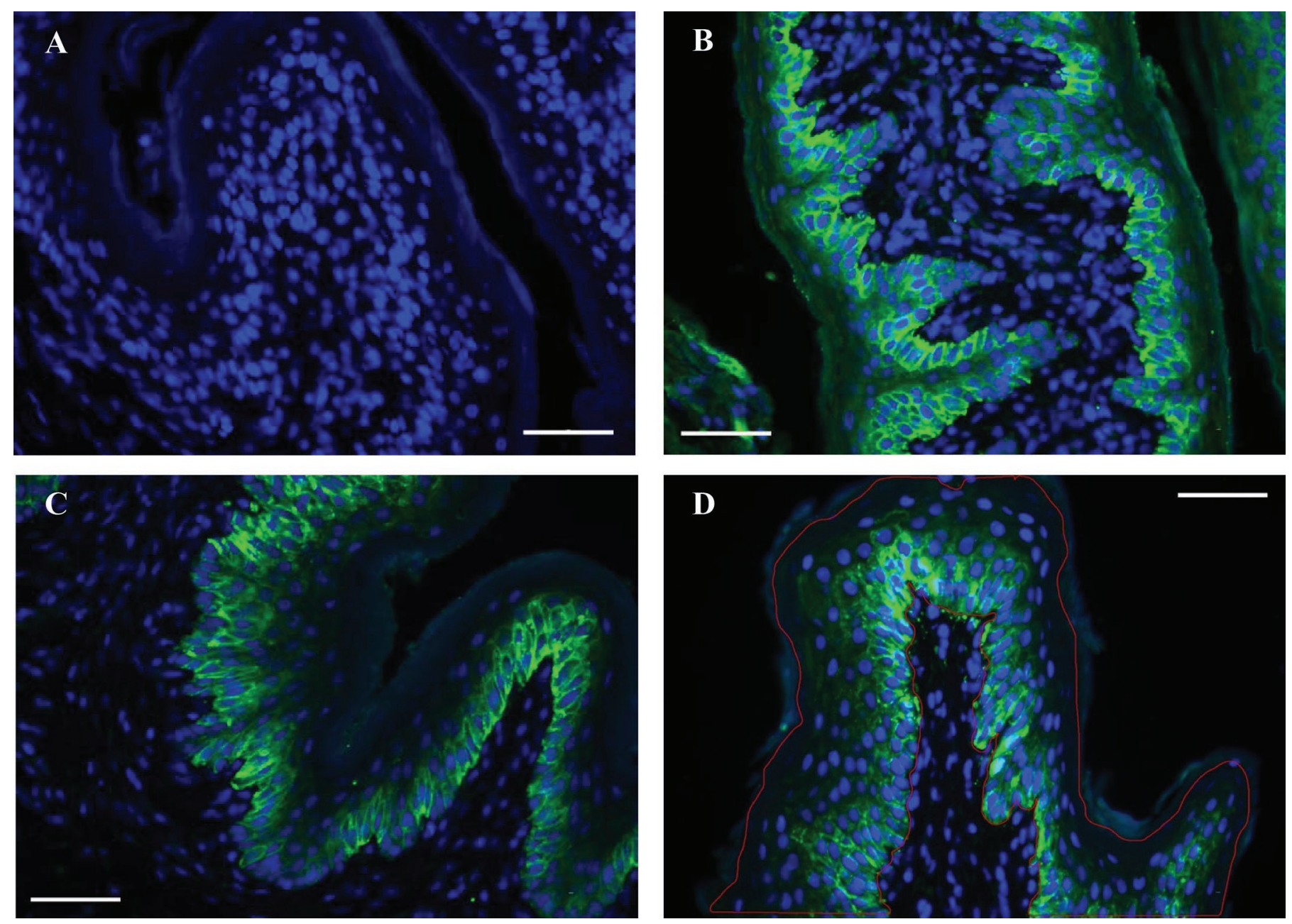

Figure 1. Representative immunohistochemical images showing the intensity of staining for monocarboxylate transporter 1 (MCT1) protein in the rumen of milk replacer only (MRO) calves and milk replacer and starter (MRS) calves during the 6-wk trial. Green staining indicates MCT1 protein abundance and blue staining indicates nuclei. (A) Negative control of MCT1; (B) MRO staining of MCT1 protein; (C) MRS staining of MCT1 protein; (D) image showing red outline of epithelial area used to calculate the intensity per unit area to assess the level of protein abundance of MCT1 in rumen epithelium. Scale bars represent $50 \mu \mathrm{m}$.

\section{Statistical Analyses}

Intake, growth, qPCR, and IHC data were analyzed using the MIXED procedure of SAS 9.4 (SAS Institute, Cary, NC). All models included the fixed effects of treatment, with repeated measures data (intake and growth) including week and the interaction of treatment and week. Calf nested within treatment was the random effect in all models. Period was initially included in all models, but was found to be nonsignificant and was removed. All analyses included the best-fit covariance structure when appropriate; denominator degrees of freedom were not specified. Best-fit covariance structures as determined by lowest Akaike information criterion were as follows: $\mathrm{ME}$ and $\mathrm{ADP}$ intake measurements used autoregressive, and BW used Toeplitz.
Data for qPCR were not normally distributed (significant Shapiro-Wilk test) and were $\log 10$ transformed and reanalyzed. Untransformed data are presented.

Absorption rates for each VFA and fluid passage rates were derived by fitting modeled VFA or Co concentrations to either the measured VFA concentration data or the measured Co concentration using the FME package of R (version 3.4.0; Soetaert and Petzoldt, 2010). The models used 2 pools: one for the substrate of interest (VFA or Co) and one for the volume of fluid in the rumen. Input to the fluid volume pool was assumed to be $40 \mathrm{~mL} / \mathrm{h}$ based on the applied infusion rates, and the initial volume was equal to the volume of buffer solution used for that animal. Input to the Co pool was $1.04 \mathrm{mg} / \mathrm{h}$ based on the rate of Co infusion, and the initial mass of Co was assumed to be 0 . The 
flux of water out of the rumen was represented by mass action kinetics, and the rate of Co removal was directly proportional to the rate of fluid removal. After Co concentrations were used to determine fluid passage, the fluid passage rate was applied to the VFA models. For each VFA, input was assumed to be 0; the initial mass was equal to the quantity of VFA in the buffer solution. The VFA pool was subject to draining by fluid passage (proportional to fluid exit rate) and absorption, which followed mass action kinetics and was fit during the derivation process. A fourth-order Runge Kutta integration algorithm was used to integrate the differential equations describing the Co, VFA, and fluid pools, and the fitting of the fractional passage or absorption rates was done by minimizing the weighted residuals of the model using a Nelder-mead optimization algorithm. In all cases, significance was declared when $P \leq 0.05$ and a tendency declared when $0.10 \geq P \geq 0.05$

\section{RESULTS AND DISCUSSION}

\section{Intake and Growth}

The dietary treatments were formulated to be both isocaloric and isonitrogenous (NRC, 2001) to prevent any confounding factors influencing rumen growth and development. As planned, ME and ADP intakes did not differ for the interaction of treatment by week $(P$ $=0.78$ and $P=0.52$, respectively) or by treatment alone $(P=0.94$ and $P=0.30$, respectively). Actual $\mathrm{ME}$ and ADP intakes for MRO calves were $3.96 \pm 0.06$ $\mathrm{Mcal} / \mathrm{d}$ and $0.17 \pm 0.01 \mathrm{~kg} / \mathrm{d}$, respectively. For MRS
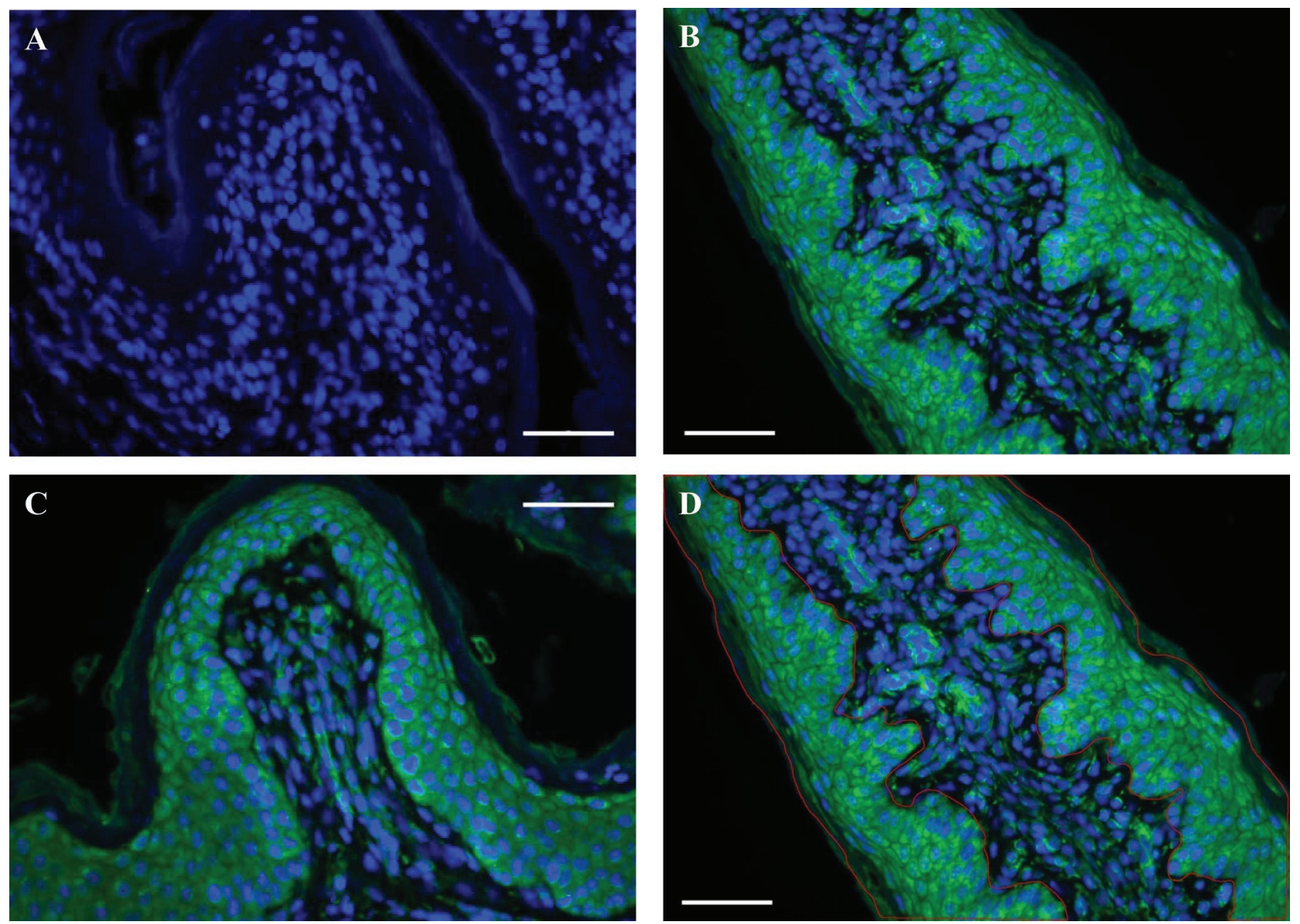

Figure 2. Representative immunohistochemical images showing the intensity of staining for monocarboxylate transporter 4 (MCT4) protein in the rumen of milk replacer only (MRO) calves and milk replacer and starter (MRS) calves during the 6-wk trial. Green staining indicates MCT4 protein abundance and blue staining indicates nuclei. (A) Negative control of MCT4; (B) MRO staining of MCT4 protein; (C) MRS staining of MCT4 protein; (D) image showing red outline of epithelial area used to calculate intensity per unit area to assess the level of protein abundance of MCT4 in rumen epithelium. Scale bars represent $50 \mu \mathrm{m}$. 
Table 4. Relative mRNA abundance (expressed as $2^{-\Delta \mathrm{Ct}}$ values; higher values equate to more mRNA) of selected genes in rumen epithelial tissue relevant to VFA transport in calves fed 2 differing diets at 6 wk of age

\begin{tabular}{|c|c|c|c|c|}
\hline \multirow[b]{2}{*}{ Gene $^{1}$} & \multicolumn{2}{|c|}{ Treatment $^{2}$} & \multirow[b]{2}{*}{ SEM } & \multirow{2}{*}{$\begin{array}{c}\text { Test of fixed } \\
\text { effects, } P \text {-value }\end{array}$} \\
\hline & MRO & MRS & & \\
\hline$M C T 1$ & $2.4 \times 10^{-2}$ & $5.4 \times 10^{-2}$ & $1.1 \times 10^{-2}$ & 0.06 \\
\hline МCT2 & $9.8 \times 10^{-4}$ & $5.1 \times 10^{-4}$ & $2.0 \times 10^{-4}$ & 0.13 \\
\hline$M C T_{4}$ & $2.9 \times 10^{-4}$ & $3.0 \times 10^{-4}$ & $1.2 \times 10^{-4}$ & 0.47 \\
\hline NHE1 & $3.1 \times 10^{-4}$ & $2.6 \times 10^{-4}$ & $1.2 \times 10^{-4}$ & 0.50 \\
\hline NHE2 & $1.6 \times 10^{-3}$ & $3.3 \times 10^{-3}$ & $1.6 \times 10^{-3}$ & 0.61 \\
\hline NHE3 & $9.1 \times 10^{-5}$ & $3.3 \times 10^{-5}$ & $2.8 \times 10^{-5}$ & 0.10 \\
\hline
\end{tabular}

calves, these were $3.95 \pm 0.06 \mathrm{Mcal} / \mathrm{d}$ and $0.18 \pm 0.01$ $\mathrm{kg} / \mathrm{d}$, respectively. At the end of the trial, MRO calves weighed $63.10 \pm 1.16 \mathrm{~kg}$ and MRS calves weighed 62.90 $\pm 1.05 \mathrm{~kg}(P=0.99)$. Also, ADG did not differ between MRO and MRS calves $(0.46 \pm 0.03 \mathrm{~kg}$ and $0.46 \pm 0.03$ $\mathrm{kg}$, respectively; $P=0.94)$.

\section{Rumen Epithelial qPCR}

The only difference between treatment for any of the VFA transport-related genes was a trend for an increase in $M C T 1$ expression for MRS compared with MRO calves $(P=0.06$; Table 4$)$. This trending increase in expression of MCT1 is interesting because of the implication of MCT1 in transporting VFA from the epithelium to the interstitial fluid/portal blood circulation (Graham et al., 2007). Laarman et al. (2012a) noted a decrease in MCT1 mRNA abundance in calves fed only MR and hay compared with MR, hay, and starter around $50 \mathrm{~d}$ of age, but no treatment in that study was MR only, and diets were not formulated to be isocaloric or isonitrogenous. The other $2 \mathrm{VFA}$ transporter genes (MCT2 and MCT4) did not exhibit any differences between treatments, which may reflect the experimental VFA buffer used, causing a uniformly increased expression of VFA transporters into the rumen epithelium (MCT4), as well as between the rumen epithelial cell layers (MCT2) based on their cellular localization (Kirat et al., 2007, 2013). The other genes examined (NHE1, NHE2, and NHE3) are relevant to VFA transport because of their ability to help regulate intracellular pH (Müller et al., 2000). We found no differences observed for the NHE genes, which also may be explained by the experimental VFA buffer that was given to both treatments. The reasoning behind this may be that the exposure of each rumen to the same $\mathrm{pH}$ controlled the concentration gradients of $\mathrm{H}^{+}, \mathrm{Na}^{+}$, $\mathrm{K}^{+}$, and other ions that may play a role in controlling the convoluted VFA transport/intracellular $\mathrm{pH}$ relationship (Connor et al., 2010). The lack of change in gene expression that we noted may also have been due to the isocaloric and isonitrogenous nature of the diets, which supplied the rumen epithelium with equal "nutrients," even if they were coming mainly from opposite sides (i.e., rumen lumen vs. blood). How these gene expression results compare with protein abundance as well as activity (i.e., VFA absorption) are discussed, but the expression of a gene does not necessarily equate with protein abundance or protein activity.

\section{Rumen Immunohistochemistry}

We expected enhanced rumen growth in the calves fed a fermentable starter diet compared with calves fed a solely liquid diet; however, we were interested primarily in whether the rumen function of these calves differed. Assessing VFA absorption involved using immunohistochemistry to measure the abundance of the VFA transporters MCT1 and MCT4, which have previously been identified in bovine rumen (Kirat et al., 2005, 2007). Images depicting the staining of both MCT1 and MCT4 in rumen tissue are shown in Figures 2 and 3. The pattern of staining of MCT1 is similar to that shown previously by Kirat et al. (2005), Graham et al. (2007), and Flaga et al. (2015) and that hypothesized by Connor et al. (2010) in the basale layer of the stratified rumen epithelium, where it is important for the movement of VFA from the epithelial tissue to the extracellular space (i.e., interstitial fluid and blood). We found no difference in the abundance of MCT1 between treatments based on the intensity measures per area of rumen epithelial tissue $(P=0.19)$, which suggests a lack of difference in the ability of the tissue to absorb VFA from a facilitated transport mode of action via protein transporter. The staining pattern of MCT4 was similar to that seen by Kirat et al. (2007), but did not 
Table 5. Mean fluid exit, VFA absorption rate, and total 6-h absorption of VFA after being exposed to a defined concentration of VFA in calves fed 2 differing forms of diet for $6 \mathrm{wk}$

\begin{tabular}{|c|c|c|c|c|}
\hline \multirow[b]{2}{*}{ Item } & \multicolumn{2}{|c|}{ Treatment $^{1}$} & \multirow[b]{2}{*}{ SEM } & \multirow{2}{*}{$\begin{array}{c}\text { Test of fixed } \\
\text { effects, } P \text {-value }\end{array}$} \\
\hline & $\mathrm{MRO}$ & MRS & & \\
\hline Fluid exit $(\% / \mathrm{h})$ & 15.70 & 10.70 & 2.85 & 0.14 \\
\hline \multicolumn{5}{|l|}{ VFA absorption $(\% / \mathrm{h})$} \\
\hline Acetate & 20.90 & 35.30 & 7.73 & 0.20 \\
\hline Propionate & 27.40 & 33.70 & 7.93 & 0.57 \\
\hline Butyrate & 41.10 & 42.00 & 10.50 & 0.95 \\
\hline \multicolumn{5}{|c|}{ Total 6-h VFA flux (mmol) } \\
\hline Acetate & 176.70 & 165.70 & 22.80 & 0.73 \\
\hline Propionate & 74.80 & 70.50 & 10.30 & 0.76 \\
\hline Butyrate & 78.80 & 75.90 & 11.80 & 0.83 \\
\hline
\end{tabular}

${ }^{1} \mathrm{MRO}=$ milk replacer only, MRS $=$ milk replacer with starter; diets were formulated to be isocaloric and isonitrogenous.

${ }^{2}$ Significance declared at $P \leq 0.05$.

seem to fit the hypothesized location by Connor et al. (2010) in the upper layers of the rumen epithelium (i.e., stratum granulosum and stratum corneum). The diffuse staining of MCT4 throughout the rumen epithelial cell layers questioned the idea that MCT4 is important mainly for transporting VFA from the ruminal lumen into the rumen epithelial cell layers. Although we considered that artifacts might have explained this staining pattern, the localization of MCT4 observed in the current study was consistent with that observed by Kirat et al. (2007), and the lack of staining in the negative control (Figure 2) seemed valid. We found no difference in the intensity of MCT4 staining between treatments $(P=0.60)$, suggesting a lack of difference in the ability of the tissue to absorb VFA from a facilitated transport mode of action via protein transporter from the rumen. Taken together, the staining results for MCT1 and MCT4 suggest that even though MRO calves were given only a liquid diet, their rumens were still just as capable of absorbing VFA as the rumens of MRS calves when both were exposed to a defined concentration of VFA. These transporter immunohistochemical results did not quantitatively assess VFA absorption, leaving open the possibility that passive diffusion could still play a role in VFA transport.

\section{VFA Absorption}

To assess VFA absorption, we recorded the concentration of VFA over a 6-h period on the last day of the trial, and we measured the liquid flow rate out of the rumen. Results in Table 5 show no differences in fluid exit rate to the omasum $(P=0.14)$, or VFA absorption rates for acetate, propionate, or butyrate $(P=$ $0.20, P=0.57$, and $P=0.95$, respectively) between the MRO and MRS calves. Also, total 6-h fluxes of acetate, propionate, or butyrate were not different between the
MRO and MRS calves $(P=0.73, P=0.76$, and $P=$ 0.83 , respectively; Table 5). When the modeled VFA absorption rates are taken together with the gene expression and transporter immunohistochemistry, they indicate that diet did not alter the ability of the rumen to absorb VFA when tested with the washed rumen technique.

Sutton et al. (1963) performed a similar study and showed that calves fed only milk had a decreased maximal absorption rate of acetate from wk 1 to 34 (stayed constant around $30 \mathrm{mg}$ of acetate/100 mL of solution/h) compared with calves fed milk, grain, and hay that increased from wk 1 (about $30 \mathrm{mg}$ of acetate/100 mL of solution/h) to 34 (about $210 \mathrm{mg}$ of acetate $/ 100 \mathrm{~mL}$ of solution/h). The results in the current study go against these earlier findings and instead support those of Khouri (1969), who noted no differ-

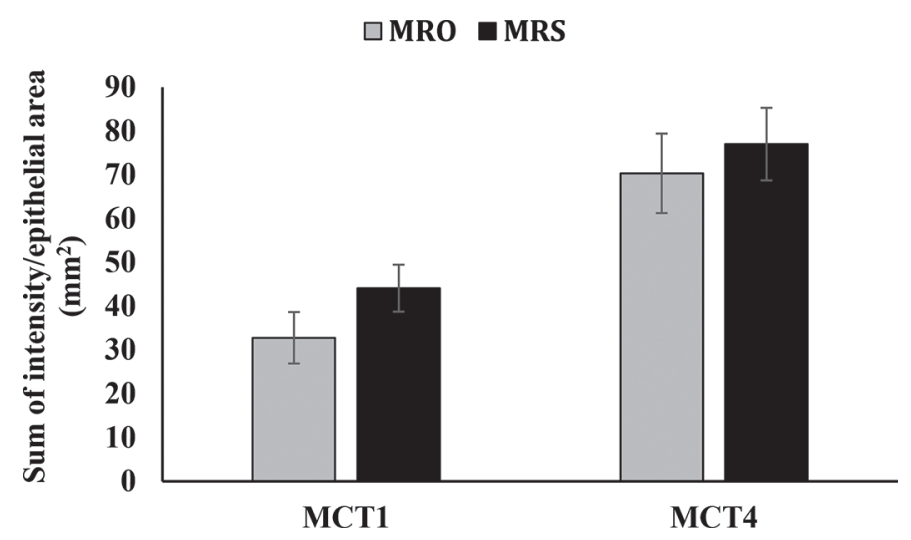

Figure 3. Mean ( \pm SEM) immunohistochemical measurements of intensity/epithelial area for VFA transporter proteins monocarboxylate transporter (MCT)1 and MCT4 in the rumen of milk replacer only (MRO) calves and milk replacer and starter (MRS) calves during the 6 -wk trial. We observed no differences for MCT1 $(P=0.19)$ or MCT4 $(P=0.60)$. 
Table 6. Mean covariate effects ( $P$-values) on VFA absorption rate and total VFA absorbed over 6 h after being exposed to a defined concentration of VFA in calves fed 2 differing forms of diet for $6 \mathrm{wk}$

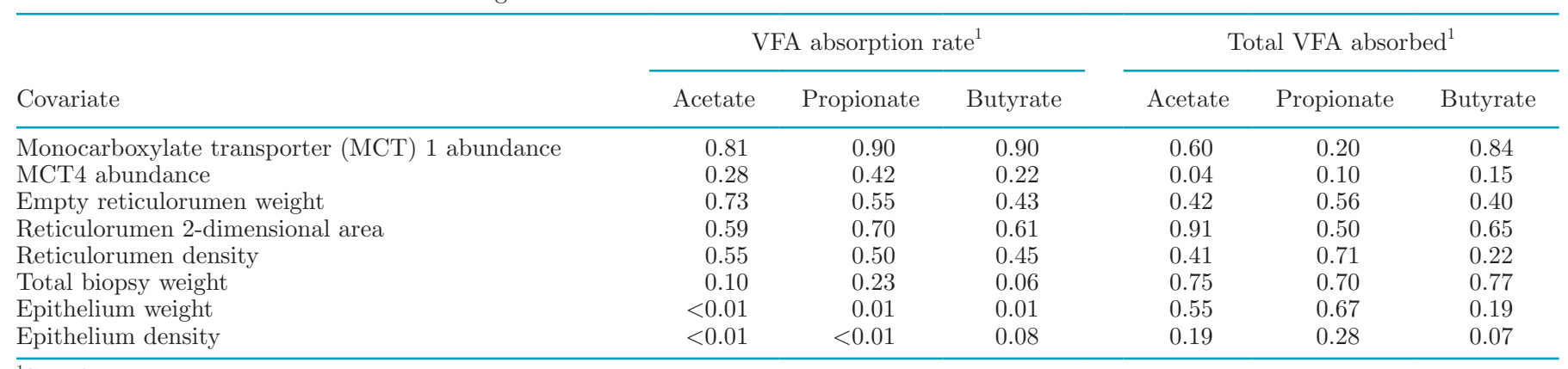

${ }^{1}$ Significance declared at $P \leq 0.05$.

ence in VFA absorption between calves fed only milk or fed milk and hay around 40 to $44 \mathrm{~d}$ of age. Rumen VFA absorption via protein-mediated transport might not explain the differences observed between the current results and those of Sutton et al. (1963), but the difference may be explained by passive diffusion of VFA because of buffer $\mathrm{pH}$ differences. Sutton et al. (1963) used a buffer $\mathrm{pH}$ of 6.5 , whereas the current study used a $\mathrm{pH}$ of 5.85. We know that $\mathrm{pH}$ has an effect on VFA absorption in the rumen, with lower $\mathrm{pH}$ resulting in enhanced passive diffusion of protonated VFA (Danielli et al., 1945; Dijkstra et al., 1993; Aschenbach and Gabel, 2000; Penner et al., 2011). The pH of 5.85 used in the current study was selected to reflect the rumen pH of 6-wk-old calves (Laarman et al., 2012b; Yohe et al., 2015). Considering that a 0.7 difference in $\mathrm{pH}$ is rather large, it is conceivable that the lower $\mathrm{pH}$ may have facilitated an increase in passive diffusion across the rumen epithelial membrane regardless of dietary treatment, resulting in a lack of effect on VFA absorption rates.

Other aspects of the paper written by Sutton et al. (1963) are vague, which could explain the differences between our studies. For example, the concentration of the buffer used in the first experiment of Sutton et al. (1963) was not described, but if it was the same buffer used in Sutton et al. (1962) then the clear differences in VFA and salt concentrations would help elucidate why we had different results. Another discussion point is that in the experiment by Sutton et al. (1963) calves fed milk, grain, and hay received rumen inoculations of adult rumen contents, whereas the milk-fed calves did not. As well, Sutton et al. (1963) did not measure the absorption rates of propionate or butyrate, so we cannot directly compare the studies. These questions are not meant to disparage the work by Sutton et al. (1963): their work was thorough and carefully executed. However, considering the uncertainties, the gap in time, and the lack of corroborating data, it is worth revisiting the question of dietary effects on preweaned calf rumen VFA absorption.

Another aspect of VFA absorption that was not explored by Sutton et al. (1963) or in the current study is epithelial blood flow. Previous work has demonstrated the importance of epithelial blood flow for VFA absorption (Storm et al., 2011, 2012). Dietary considerations that may have affected blood flow are CP intake (Storm et al., 2011) and butyrate concentration (Dobson et al., 1971), but considering that the diets were isonitrogenous and the buffers introduced into the rumen contained the same concentration of butyrate, it is fair to assume that these did not have an effect. Storm et al. (2012) demonstrated that rumen epithelial metabolism of VFA may influence blood flow, which may have been altered in the current study due to larger papillae (Table 6), a tendency for heavier epithelial biopsy weight (Table 6), and thicker epithelial cell layer (Yohe et al., 2019) leading to an increased opportunity for VFA metabolism in the rumen epithelium. In the end, we did not measure blood flow and we found no apparent differences in VFA absorption, so none of these speculations can be confirmed.

We also considered other factors when assessing rumen VFA absorption, shown in Table 6 . The covariate had an effect in only a handful of instances. One of these was a tendency for total rumen biopsy weight to influence acetate and butyrate absorption rate $(P=$ 0.10 and $P=0.06$, respectively). Increased epithelial biopsy weight was positively associated with acetate, propionate, and butyrate absorption rate $(P<0.01, P$ $=0.01$, and $P=0.01$, respectively). Finally, a denser epithelium increased acetate and propionate absorption rate $(P<0.01$ and $P<0.01$, respectively $)$ and had a trending influence on butyrate absorption rate $(P=$ 0.08). All of these results support the idea that a more developed rumen (i.e., thicker and heavier epithelium) influences VFA absorption rate. This was shown by Sutton et al. (1963), but was not demonstrated in our 
results. The reason for this lack of difference in our VFA absorption rates is unclear, but perhaps data used to perform the power analysis was not representative, affecting our ability to detect statistical differences. Interestingly, though, when looking at total VFA absorbed over the $6 \mathrm{~h}$ period, the only trending influence relevant to rumen growth was epithelial density and total butyrate absorbed $(P=0.07)$. As well, MCT4 protein abundance had an effect on total acetate absorbed $(P=0.04)$ and a trending influence on total propionate absorbed $(P=0.10)$. These data indicate that butyrate tends to undergo passive diffusion more readily than acetate and propionate, which will instead use protein-mediated transport. This supports the commentary of Bergman (1990) that rate of ruminal VFA absorption increased with increasing VFA chain length because passive diffusion is a quicker process.

\section{CONCLUSIONS}

Our hypothesis was not supported: form of calf diet, whether solely MR or MR and starter, did not alter VFA absorption when the rumen was exposed to a defined concentration of VFA at 6 wk of age. This finding was supported by a lack of difference in the abundance of protein transporters (MCT1 and MCT4) and by rates of VFA absorption and total VFA absorbed during the $6 \mathrm{~h}$ experimental period. The transport of VFA via passive diffusion also did not seem to be altered in preweaning calves under the experimental conditions. Total VFA absorption was most likely increased in calves fed MR and starter compared with MR only because they had larger rumens and increased rumen surface area. Regardless, these results indicate the rumen has the innate ability to absorb VFA, regardless of external stimuli.

\section{ACKNOWLEDGMENTS}

Carrie A. Ceh, a graduate student at Virginia Tech (Blacksburg, VA), helped with calf feeding and care. We thank R. Michael Akers, Rebecca R. Cockrum (Virginia Tech) and Erin E. Connor (USDA, Beltsville, MD) for serving on Yohe's PhD guidance committee and for providing editorial input on this manuscript. This work was supported by the Virginia Agricultural Experiment Station (Blacksburg, VA) and the USDA National Institute of Food and Agriculture (Washington, DC). Additionally, N. R. Hardy was the recipient of a John Lee Pratt Summer Research Internship grant (Virginia Tech); funds supported the gene expression work reported herein.

\section{REFERENCES}

Aschenbach, J. R., and G. Gabel. 2000. Effect and absorption of histamine in sheep rumen: Significance of acidotic epithelial damage. J. Anim. Sci. 78:464-470.

Bergman, E. N. 1990. Energy contributions of volatile fatty acids from the gastrointestinal tract in various species. Physiol. Rev. 70:567-590.

Connor, E. E., R. L. Baldwin, C. J. Li, R. W. Li, and H. Chung. 2013. Gene expression in bovine rumen epithelium during weaning identifies molecular regulators of rumen development and growth. Funct. Integr. Genomics 13:133-142.

Connor, E. E., R. W. Li, R. L. Baldwin, and C. Li. 2010. Gene expression in the digestive tissues of ruminants and their relationships with feeding and digestive processes. Animal 4:993-1007.

Danielli, J. F., M. W. Hitchcock, R. A. Marshall, and A. T. Phillipson. 1945. The mechanism of absorption from the rumen as exemplified by the behaviour of acetic, propionic and butyric acids. J. Exp. Biol. 22:75-84.

Daniels, K. M., A. V. Capuco, M. L. McGilliard, R. E. James, and R. M. Akers. 2009. Effects of milk replacer formulation on measures of mammary growth and composition in holstein heifers. J. Dairy Sci. 92:5937-5950.

Dijkstra, J., H. Boer, J. Van Bruchem, M. Bruining, and S. Tamminga. 1993. Absorption of volatile fatty acids from the rumen of lactating dairy cows as influenced by volatile fatty acid concentration, ph and rumen liquid volume. Br. J. Nutr. 69:385-396.

Dobson, A., A. F. Sellers, and S. O. Thorlacius. 1971. Limitation of diffusion by blood flow through bovine ruminal epithelium. Am. J. Physiol. 220:1337-1343.

EPA. 1998. Standard Methods for the Examination of Water and Wastewater. 20th ed. United Book Press, Baltimore, MD.

Flaga, J., P. Gorka, R. Zabielski, and Z. M. Kowalski. 2015. Differences in monocarboxylic acid transporter type 1 expression in rumen epithelium of newborn calves due to age and milk or milk replacer feeding. J. Anim. Physiol. Anim. Nutr. (Berl.) 99:521-530.

Flatt, W. P., R. G. Warner, and J. K. Loosli. 1958. Influence of purified materials on the development of the ruminant stomach. J. Dairy Sci. 41:1593-1600.

Frieten, D., C. Gerbert, C. Koch, G. Dusel, K. Eder, E. Kanitz, J. M. Weitzel, and H. M. Hammon. 2017. Ad libitum milk replacer feeding, but not butyrate supplementation, affects growth performance as well as metabolic and endocrine traits in Holstein calves. J. Dairy Sci. 100:6648-6661.

Gelsinger, S. L., A. J. Heinrichs, and C. M. Jones. 2016. A metaanalysis of the effects of preweaned calf nutrition and growth on first-lactation performance. J. Dairy Sci. 99:6206-6214.

Graham, C., I. Gatherar, I. Haslam, M. Glanville, and N. L. Simmons. 2007. Expression and localization of monocarboxylate transporters and sodium/proton exchangers in bovine rumen epithelium. Am. J. Physiol. Regul. Integr. Comp. Physiol. 292:R997-R1007.

Harrison, H. N., R. G. Warner, E. G. Sander, and J. K. Loosli. 1960. Changes in the tissue and volume of the stomachs of calves following the removal of dry feed or consumption of inert bulk. J. Dairy Sci. 43:1301-1312.

Jasper, J., and D. M. Weary. 2002. Effects of ad libitum milk intake on dairy calves. J. Dairy Sci. 85:3054-3058.

Khouri, R. H. 1969. Absorption of steam volatile fatty acids from reticulo-rumen of anaesthetised calves. N. Z. J. Agric. Res. 12:299 312 .

Kirat, D., H. Inoue, H. Iwano, K. Hirayama, H. Yokota, H. Taniyama, and S. Kato. 2005. Expression and distribution of monocarboxylate transporter 1 (MCT1) in the gastrointestinal tract of calves. Res. Vet. Sci. 79:45-50.

Kirat, D., Y. Matsuda, N. Yamashiki, H. Hayashi, and S. Kato. 2007 Expression, cellular localization, and functional role of monocarboxylate transporter 4 (MCT4) in the gastrointestinal tract of ruminants. Gene 391:140-149.

Kirat, D., K. I. Sallam, and S. Kato. 2013. Expression and cellular localization of monocarboxylate transporters (MCT2, MCT7, and 
MCT8) along the cattle gastrointestinal tract. Cell Tissue Res. 352:585-598.

Kristensen, N. B. 2000. Quantification of whole blood short-chain fatty acids by gas chromatographic determination of plasma 2-chloroethyl derivatives and correction for dilution space in erythrocytes. Acta Agric. Scand. A Anim. Sci. 50:231-236.

Kristensen, N. B., M. Engbaek, M. Vestergaard, and D. L. Harmon. 2010. Technical note: Ruminal cannulation technique in young holstein calves: Effects of cannulation on feed intake, body weight gain, and ruminal development at six weeks of age. J. Dairy Sci. 93:737-742.

Laarman, A. H., A. L. Ruiz-Sanchez, T. Sugino, L. L. Guan, and M. Oba. 2012a. Effects of feeding a calf starter on molecular adaptations in the ruminal epithelium and liver of Holstein dairy calves. J. Dairy Sci. 95:2585-2594.

Laarman, A. H., T. Sugino, and M. Oba. 2012b. Effects of starch content of calf starter on growth and rumen $\mathrm{pH}$ in Holstein calves during the weaning transition. J. Dairy Sci. 95:4478-4487.

Lengemann, F. W., and N. N. Allen. 1959. Development of rumen function in the dairy calf. 2. Effect of diet upon characteristics of the rumen flora and fauna of young calves. J. Dairy Sci. 42:11711181.

Lesmeister, K. E., and A. J. Heinrichs. 2004. Effects of corn processing on growth characteristics, rumen development, and rumen parameters in neonatal dairy calves. J. Dairy Sci. 87:3439-3450.

Müller, F., J. R. Aschenbach, and G. Gabel. 2000. Role of $\mathrm{Na}^{+} / \mathrm{H}^{+}$ exchange and $\mathrm{HCO}_{3}{ }^{-}$transport in phi recovery from intracellular acid load in cultured epithelial cells of sheep rumen. J. Comp. Physiol. B 170:337-343.

NRC (National Research Council). 2001. Nutrient Requirements of Dairy Cattle. 7th rev. ed. Natl. Acad. Press, Washington, DC.

Penner, G. B., M. A. Steele, J. R. Aschenbach, and B. W. McBride. 2011. Ruminant nutrition symposium: Molecular adaptation of ruminal epithelia to highly fermentable diets. J. Anim. Sci. 89:11081119.

Schäff, C. T., J. Gruse, J. Maciej, M. Mielenz, E. Wirthgen, A. Hoeflich, M. Schmiche, R. Pfuhl, P. Jawor, T. Stefaniak, and H. M. Hammon. 2016. Effects of feeding milk replacer ad libitum or in restricted amounts for the first five weeks of life on the growth, metabolic adaptation, and immune status of newborn calves. PLoS One 11:e0168974.

Soberon, F., E. Raffrenato, R. W. Everett, and M. E. Van Amburgh. 2012. Preweaning milk replacer intake and effects on long-term productivity of dairy calves. J. Dairy Sci. 95:783-793.

Soberon, F., and M. E. Van Amburgh. 2013. Lactation Biology Symposium: The effect of nutrient intake from milk or milk replacer of preweaned dairy calves on lactation milk yield as adults: A metaanalysis of current data. J. Anim. Sci. 91:706-712.

Soetaert, K., and T. Petzoldt. 2010. Inverse modelling, sensitivity and Monte Carlo analysis in $\mathrm{R}$ using package FME. J. Stat. Softw. $33: 1-28$.
Storm, A. C., M. D. Hanigan, and N. B. Kristensen. 2011. Effects of ruminal ammonia and butyrate concentrations on reticuloruminal epithelial blood flow and volatile fatty acid absorption kinetics under washed reticulorumen conditions in lactating dairy cows. J. Dairy Sci. 94:3980-3994.

Storm, A. C., N. B. Kristensen, and M. D. Hanigan. 2012. A model of ruminal volatile fatty acid absorption kinetics and rumen epithelial blood flow in lactating Holstein cows. J. Dairy Sci. 95:2919-2934.

Suarez-Mena, F. X., A. J. Heinrichs, C. M. Jones, T. M. Hill, and J. D. Quigley. 2015. Digestive development in neonatal dairy calves with either whole or ground oats in the calf starter. J. Dairy Sci. 98:3417-3431

Suarez-Mena, F. X., A. J. Heinrichs, C. M. Jones, T. M. Hill, and J. D. Quigley. 2016. Straw particle size in calf starters: Effects on digestive system development and rumen fermentation. J. Dairy Sci. 99:341-353.

Sutton, J. D., N. L. Jacobson, and A. D. Mcgilliard. 1962. Technique for determining ability of reticulorumen of young calves to absorb volatile fatty acids at controlled pH. J. Dairy Sci. 45:1357-1362.

Sutton, J. D., A. D. Mcgilliard, and N. L. Jacobson. 1963. Functional development of rumen mucosa. 1. Absorptive ability. J. Dairy Sci. 46:426-436.

Tamate, H., R. Getty, A. D. Mcgilliard, and N. L. Jacobson. 1962. Effect of various dietaries on anatomical development of stomach in calf. J. Dairy Sci. 45:408-420.

Tucker, H. L., C. L. Parsons, S. Ellis, M. L. Rhoads, and R. M. Akers. 2016. Tamoxifen impairs prepubertal mammary development and alters expression of estrogen receptor alpha (esr1) and progesterone receptors (PGR). Domest. Anim. Endocrinol. 54:95-105.

Warner, R. G., and W. P. Flatt. 1965. Anatomical development of the ruminant stomach. Pages 24-38 in Physiology of Digestion in the Ruminant. R. W. Dougherty, ed. Butterworths, Washington, DC.

Warner, R. G., W. P. Flatt, and J. K. Loosli. 1956. Dietary factors influencing the development of the ruminant stomach. J. Agric. Food Chem. 4:788-792.

Yohe, T. T., K. M. O'Diam, and K. M. Daniels. 2015. Growth, ruminal measurements, and health characteristics of Holstein bull calves fed an Aspergillus oryzae fermentation extract. J. Dairy Sci. 98:6163-6175.

Yohe, T. T., H. Schramm, C. L. M. Parsons, R. R. White, and K. M. Daniels. 2018. Technical note: Infusion, sampling, and vacuumassisted collection devices for use in ruminally cannulated calves. J. Dairy Sci. 101:9065-9071.

Yohe, T. T., H. Schramm, C. L. M. Parsons, H. L. M. Tucker, B. D. Enger, N. R. Hardy, and K. M. Daniels. 2019. Form of calf diet and the rumen. I: Impact on growth and development. J. Dairy Sci. 102:8486-8501. https://doi.org/10.3168/jds.2019-16449. 